\title{
Case studies using 3D technologies for corrective osteotomies : synergy between engineer and surgeon
}

\author{
Els Bryunooghe \\ From 10th Congress of the Asia-Pacific Federation of Societies of Surgery fo the Hand and the 6th Congress \\ of Asia-Pacific Federation of Societies of Hand Therapists \\ Kuala Lumpur, Malaysia. 2-4 October 2014
}

Three-dimensional (3D) visualization, surgical pre-planning, and 3D printing or additive manufacturing of patient specific instruments and implants are fast gaining attention in the medical world. Already widely used in cranio-maxillofacial, dental, and total knee replacement surgery, 3D technologies are now starting to create a trend in the upper limb region too.

A crucial step in establishing successful synergy between $3 \mathrm{D}$ technology and the orthopaedic world is to thoroughly get to know one another. Technology companies should constantly be aware of the changing needs of the medical field and be ready to evolve where and when needed. The medical field, in turn, should be aware of the new possibilities this technology offers but also mindful of its limitations. This is true in general and maybe even more so for corrective osteotomies in the upper limb, where current techniques mostly rely on two-dimensional(2D) X-rays and mass-standardized implant designs to solve often complex and extremely individualized malformations.

In day to day practice, this synergy starts with an orthopaedic surgeon virtually planning his/her surgery together with the (clinical) engineer. Using Materialise solutions (Materialise N.V, Leuven, Belgium), nearly 500 upper-and lower limb cases have been completed with this personalized approach globally. It requires the surgeon and the engineer to, 'sit together', as it were, during online web sessions to discuss the case and to find the preferred solution for each individual patient.

Applications for this 3D technology range from malunited distal and diaphyseal extra-articular fractures to intra-articular fractures with more than 2 distal fragments, rare forms of radio-ulnar synostosis, cubitus

Materialise, Antwerp, 2930, Belgium 


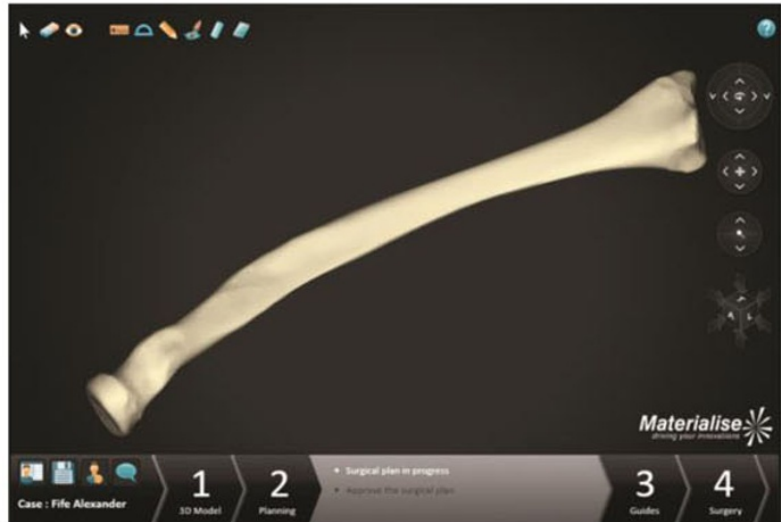

Pre-operative deformed radius in virtual environment

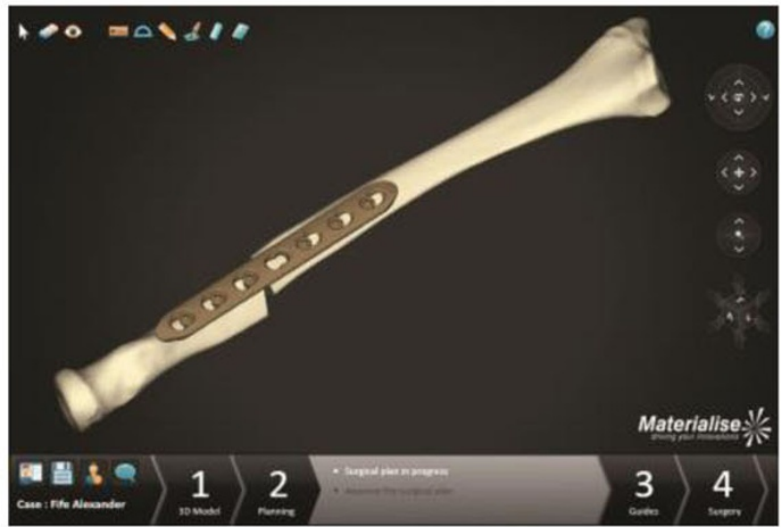

Planned position of cut radius with plate in ideal position in virtual environment

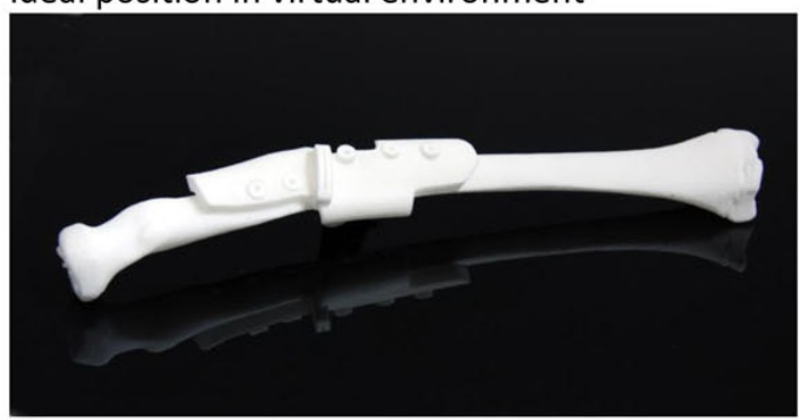

Patient specific drilling guide positioned on deformed radius both produced using additive manufacturing

\section{Figure 1}

The potential applications of this technology are boundless, but the limitations must be carefully considered as well. For example, simulation of the behavior of the soft tissue after correction still remains uncertain. Although the goal of the surgical plan is to achieve a bony

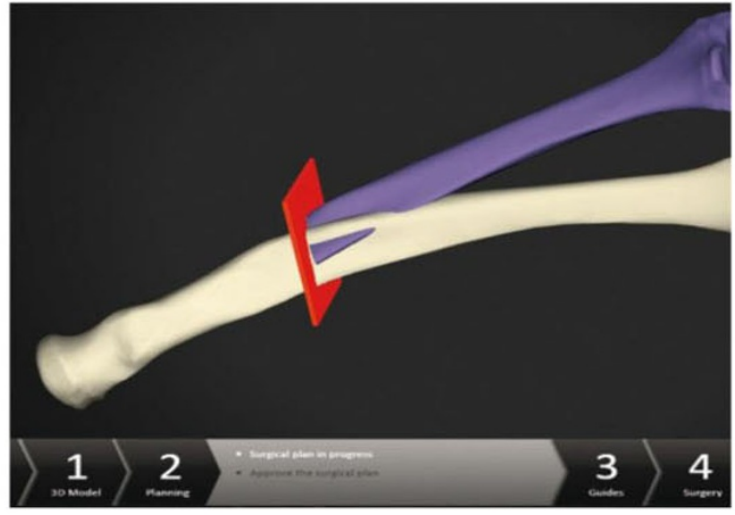

Pre-operative deformed radius (bone colour) overlayed on normal contra-lateral side(purple) with red plane defining osteotomy level in virtual environment

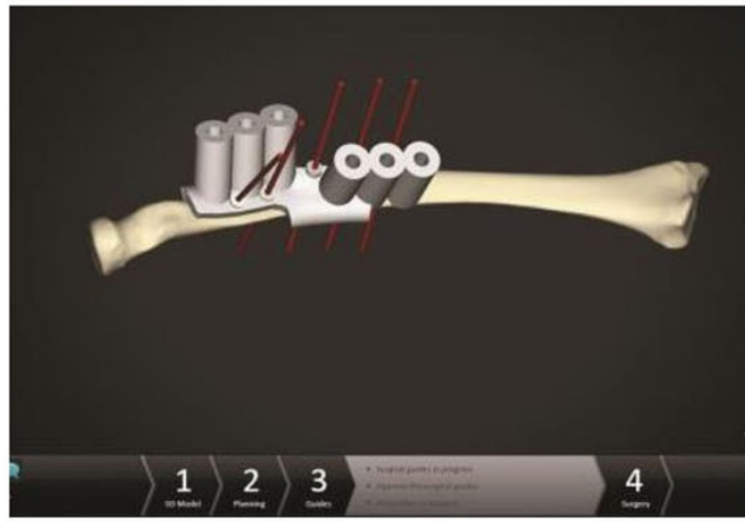

Drilling guide positioned on pre-operative radius in virtual environment

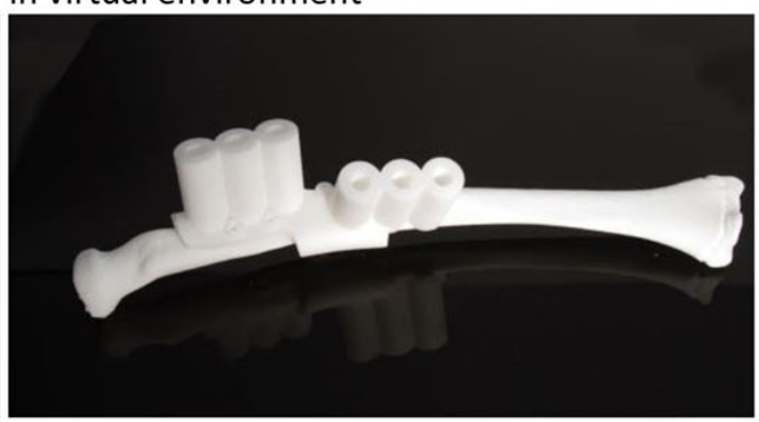

Patient specific cutting guide positioned on deformed radius both produced using additive manufacturing

anatomical restoration, there is no guarantee that the soft tissues will allow this bony restoration to regain full prosupination and/or flexion-extension. Additionally, in cases where a healthy contralateral side is unavailable or bilateral congenital deformities are involved, the surgical plan 
is even more dependent on the surgeon's experience to correct the malunion in the most suitable way.

Provided each other's strengths and limitations are taken into consideration, synergy between an engineer and a surgeon can become the foundation for revolutionizing the way orthopaedic surgery is done. It is clear the future holds more exciting new opportunities.

Published: 19 May 2015

doi:10.1186/1753-6561-9-S3-A92

Cite this article as: Bryunooghe: Case studies using 3D technologies for corrective osteotomies : synergy between engineer and surgeon. $B M C$

Proceedings 2015 9(Suppl 3):A92.

Submit your next manuscript to BioMed Central and take full advantage of:

- Convenient online submission

- Thorough peer review

- No space constraints or color figure charges

- Immediate publication on acceptance

- Inclusion in PubMed, CAS, Scopus and Google Scholar

- Research which is freely available for redistribution

Submit your manuscript at www.biomedcentral.com/submit 